\title{
UM ESTUDO SOBRE A SÍNDROME DE DOWN: IMPLICAÇÕES E DESAFIOS PARA INCLUSÃO ESCOLAR NA EDUCAÇÃO INFANTIL
}

\author{
Sidney Lopes Sanchez Junior (iD), Patrícia Ferreira Concato de Souza (D)2 \\ Natany Dayani de Souza Assai iD3 \\ Márcia Inês Schabarum Mikuska iD4
}

\section{Resumo}

Este estudo aborda a inclusão escolar de alunos com Síndrome de Down na Educação Infantil, tendo como problema de pesquisa os desafios enfrentados por professoras/es que recebem estas crianças na sala de aula regular. Como objetivo geral, se propõem analisar a percepção de três professores que atuam no ensino de crianças com Síndrome de Down na Educação Infantil, bem como discutir a importância da formação destes professores no processo de inclusão escolar. Os dados foram coletados por meio de um questionário com perguntas abertas que buscaram compreender a complexidade deste fenômeno, de modo que os resultados apontaram para uma certa dificuldade dos professores no atendimento à crianças com Síndrome de Down na Educação Infantil devido à falta de formação específica e capacitação para atuarem frente aos desafios da inclusão escolar.

Palavras-chave: Educação Infantil; Inclusão; Síndrome de Down; Formação de professores.

\section{A STUDY ON DOWN SYNDROME: IMPLICATIONS AND CHALLENGES FOR SCHOOL INCLUSION IN EARLY CHILDHOOD EDUCATION}

\section{Abstract}

This study addresses the school inclusion of students with Down Syndrome in Early Childhood Education, having as a research problem the challenges faced by teachers who receive these children in the regular class. As a general objective, it is proposed to analyze the perception of three teachers who work in the teaching of children with Down Syndrome in Early Childhood Education, as well as to discuss the importance of training these teachers in the process of school inclusion. The data were collected through a questionnaire with open

\footnotetext{
${ }^{1}$ Doutorando em Educação pela Universidade Estadual de Londrina (UEL). Docente na Faculdade de Filosofia, Ciências e Letras de Mandaguari (FAFIMAN).

${ }^{2}$ Mestre em Ensino pelo Programa de Mestrado Profissional em Ensino da Universidade Estadual do Norte do Paraná (UENP). Docente na Prefeitura Municipal de Cornélio Procópio - PR.

${ }^{3}$ Doutora em Ensino de Ciências e Educação Matemática pela UEL. Docente do Departamento de Química no Instituto de Ciências Exatas da Universidade Federal Fluminense (UFF) - Volta Redonda.

${ }^{4}$ Doutoranda em Metodologias para o Ensino de Linguagens e suas Tecnologias (UNOPAR). Técnica Administrativa em Educação na Universidade Federal do Paraná (UFPR) - Campus Jandaia do Sul.
} 
questions that sought to understand the complexity of this phenomenon, so that the results pointed to a certain difficulty for teachers in caring for children with Down Syndrome in Early Childhood Education due to the lack of specific training and training to face the challenges of school inclusion.

Keywords: Child education; Inclusion; Down's syndrome; Teacher training.

\section{Introdução}

A inclusão tem sido um tema amplamente debatido na área da Educação, visto a necessidade de mudanças do sistema educacional pautadas nas demandas sociais. Tal movimento inclusivo articula adaptações das escolas, sejam elas curriculares, físicas, estruturais, pedagógicas e organizacionais, de maneira que atenda as especificidades das diferenças e deficiências que podem chegar ao ambiente escolar.

De acordo com a Lei de Diretrizes e Base da Educação 9.394/96 em seu artigo 58 que trata da modalidade Educação Especial, destaca que esta deve ser oferecida preferencialmente na rede regular de ensino para educandos com deficiência, transtornos globais do desenvolvimento, altas habilidades e superdotação (BRASIL, 1996); o que representa um avanço em termos de políticas públicas para atendimento das pessoas com deficiência.

Recentemente, por meio do Decreto de n²10.502 de setembro de 2020, o Ministério da Educação homologa a nova Política Nacional de Educação Especial Equitativa, Inclusiva e com Aprendizado ao longo da vida (BRASIL, 2020) que tem com pressuposto a valorização das singularidades e a garantia do direito do estudante e famílias decidirem sobre a alternativa mais adequada para atendimento educacional especializado. De modo que assegura o direito do cidadão público alvo da Educação Especial se matricular na instituição de ensino que lhe garanta melhores condições de atendimento.

Este trabalho elege a Síndrome de Down (SD) como foco da pesquisa, entendendo essa síndrome não como uma doença, mas uma condição da pessoa que pode condicionar ou favorecer a presença de quadros patológicos; sendo uma síndrome genética com variações que podem causar atraso intelectual nos indivíduos acometidos (SÉRES, 2011).

Pesquisadores como Schwartzmann (2003), Mantoan (2003), Dea (2009) e Seno e colaboradores (2014) elucidam que crianças com Síndrome de Down possuem complicações no desenvolvimento físico e intelectual que podem comprometer o desenvolvimento de habilidades psicomotoras e também da linguagem oral. Ademais, há como outra característica a ocorrência de disfluência da fala tanto em conversas quanto no processo de escrita.

A pessoa com Síndrome de Down pode apresentar características fenotípicas como: perfil achatado; nariz pequeno e achatado; hipoplásica (diminuição da atividade dos 27 tecidos da face); boca e dentes pequenos, de forma que a língua pode projetar-se para fora; língua hipotônica, podendo 
apresentar estrias; céu da boca ou palato estreito; cabelos finos e lisos; pregas epicântica ou pregas pálpebras nasais podem se estender do nariz até a parte interna da sobrancelha, cobrindo o canto interno do olho; orelhas pequenas, de modo que a borda superior da orelha se encontre dobrada e os canais do ouvido estreitos; prega palmar transversal única; mãos e pés tendem a ser pequenos e grossos; distância entre os dedos dos pés, especialmente entre o dedão e o segundo dedo; as mãos podem ocorrer o encurvamento dos quintos dígitos; e parte posterior da cabeça levemente achatada (SCHWARTZMANN, 2003).

A obesidade, nas ocasiões que acomete indivíduos com Síndrome de Down é um fator que pode dificultar o desenvolvimento motor, uma vez que o excesso de peso sobrecarrega todas as partes do corpo (GIONGO et al., 2009). A deficiência mental também é uma das características mais presentes em crianças com SD, e devido ao comprometimento da linguagem oral, a criança se utiliza do contato visual e dos gestos para se comunicar e expressar os seus desejos (SILVA; DESSEN, 2002).

Diante de tais características apresentadas, quando há um diagnóstico de SD, os estímulos devem iniciar o quanto antes para evitar maiores prejuízos na qualidade de vida do indivíduo. Assim, a Educação Infantil (EI) como primeira etapa da Educação Básica e o primeiro contato da criança com o ambiente escolar, deve ser acolhedor, planejado e qualificado para receber e atender todas as crianças, bem como as com SD.

Posto isso, essa pesquisa se dá no contexto da Educação Infantil, tendo como objetivos analisar o relato de professoras que atuam nesta etapa da Educação Básica acerca dos desafios da inclusão e atendimento de crianças com SD, bem como destacar aspectos relevantes da formação destes professores. Assumimos o compromisso em discorrer de maneira sucinta sobre a Síndrome de Down que será abordado na próxima seção.

\section{A Síndrome de Down - História e Definições}

Segundo Schwartzman (2003) a Síndrome de Down sempre esteve presente na espécie humana em todos os momentos da história, bem antes dos estudos científicos; que só tiveram início a partir do século XIX. Assim, cada lugar compreendia essa síndrome de maneira diferente, conforme sua cultura. Como por exemplo, na cultura dos Olmecas, as crianças que nasciam com a Síndrome de Down eram consideradas um ser híbrido, um deus-humano; contudo, nas sociedades europeias, essas crianças eram abandonadas logo que nasciam. Para os gregos, as crianças que nasciam com Síndrome de Down eram vistas como aberração (SCHWARTZMAN, 2003).

Segundo Werneck (1995), a história da SD no mundo começa no século XIX, até então, os deficientes intelectuais eram vistos como um único grupo homogêneo, sendo tratados e medicados identicamente, sem levar em consideração as causas da deficiência, que podem ser inúmeras. Em 1866, 0 cientista John Langdon Down, iniciou os estudos que ajudaram a difundir o conceito da Síndrome de Down como uma entidade clínica peculiar e a 
diferenciá-la do hipotireoidismo congênito ou cretinismo, condição bastante frequente naquela época. John Langdon Down trabalhou como superintendente em um "asilo de idiotas"; como eram denominados os lugares onde eram atendidas pessoas com deficiências; foi neste lugar que deu início às suas pesquisas, analisando pessoas com deficiências mentais, chegando à conclusão que as pessoas com Síndrome de Down possuem características que os diferem de outros deficientes (SCHWARTZMAN, 2003).

Em 1959, o Dr. Jerôme Lejeune descobriu que as pessoas com Síndrome de Down possuem um cromossomo a mais, sendo denominado de "trissomia 21"; o que fez com que as pessoas com Síndrome de Down deixassem de ser chamadas de "mongolóides"; categoria considerada como uma sub-raça humana (SCHWARTZMAN, 2003). Tal descoberta, impulsionou muitas investigações acerca do desenvolvimento cognitivo da pessoa com Síndrome de Down, especialmente nos Estados Unidos e Inglaterra, com intuito de compreender e auxiliar as pessoas nessa condição a melhorarem suas vidas e desmistificar conceitos construídos e impostos pela sociedade ao longo dos anos (BISSOTO, 2005).

Schwartzman (2003) afirma que quase todo o caso de Síndrome de Down é causado por um erro na divisão celular, suficiente para causar modificações no desenvolvimento embrionário. Para comprovar a síndrome é necessário que seja feito um diagnóstico por meio de um exame genético denominado cariótipo. Dea et al., (2009), explica que todas as células do corpo humano possuem 46 cromossomos que são divididos em pares, no caso da pessoa com esta síndrome, o número de cromossomos presente nas células é diferente do convencional, pois existe um cromossomo extra no par 21, assim a pessoa receberá 47 cromossomos.

É importante destacar que a Síndrome de Down pode ser classificada em três tipos, sendo a Trissomia 21, Translocação e Mosaicismo. A translocação também possui um cromossomo a mais no par 21 , mas de modo que o cromossomo extra do par 21 está conectado a outro cromossomo, normalmente ao cromossomo 14 ou ao cromossomo 21. O mosaicismo ocorre nas primeiras divisões celulares após a fertilização, e ocorre a não disjunção do par do cromossomo 21, originando então um cromossomo extra neste par, de modo que uma célula terá 47 cromossomos.

A figura 01 a seguir, ilustra as células do cromossomo e suas manifestações: Trissomia 21, Translocação e Mosaicismo. 


\section{Figura 01 - Tipos de Trissomia}
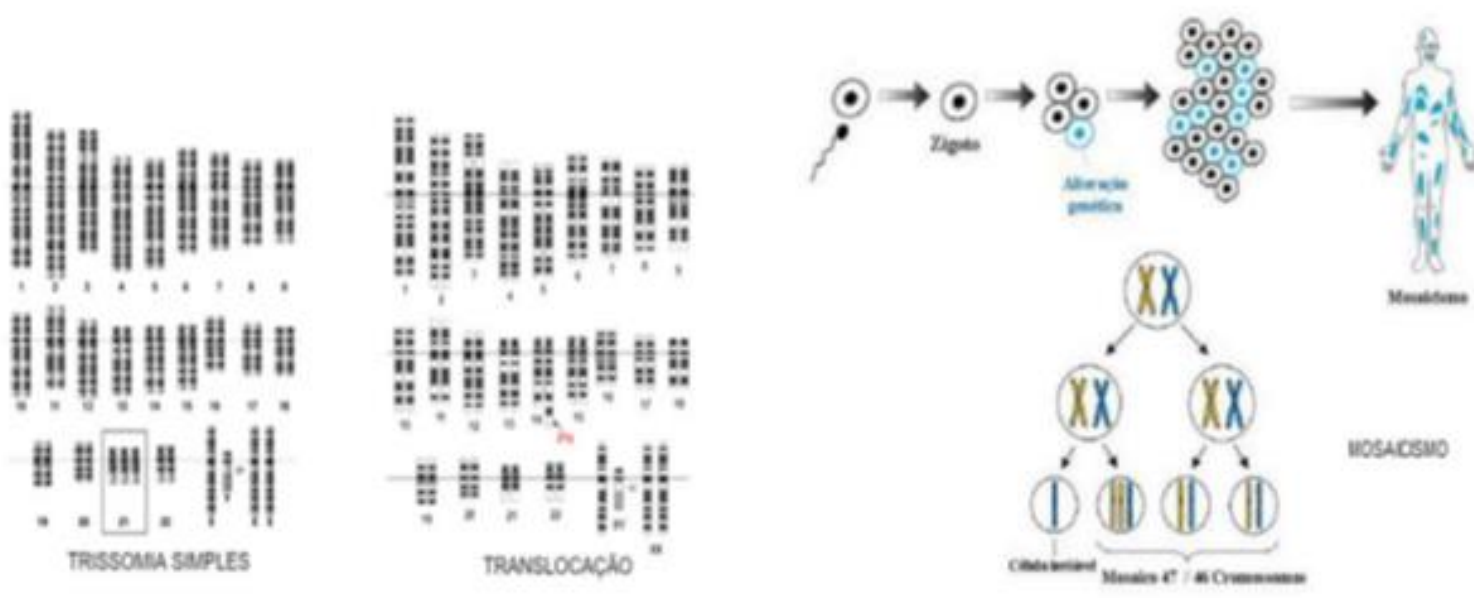

Fonte: Teles (2012. p. 14).

Ao compreender características históricas e genéticas da SD, torna-se evidente que estes sujeitos precisam de atendimento especializado e qualificado em todos os níveis e etapas da Educação, algo que que não se faz sem investimento em políticas públicas e formação de professores, temáticas que serão tratados no tópico seguinte.

\section{Educação Inclusiva e a Formação de Professores}

A Constituição Federal de 1988 prevê no artigo 205 que a Educação é um direito de todos e dever do Estado e da família, e será promovida e incentivada com a colaboração da sociedade, visando ao pleno desenvolvimento da pessoa, seu preparo para o exercício da cidadania e sua qualificação para o trabalho (BRASIL, 1988). Essa determinação é retomada na Lei de Diretrizes e Bases da Educação Nacional (LDBEN) (BRASIL, 1996) no que tange ao direito à Educação.

Cabe destacar que esses avanços foram construídos historicamente por movimentos e lutas para alcançar os direitos das pessoas com deficiência, e vale destacar a Declaração de Salamanca (1994), sendo um documento elaborado na Conferência Mundial sobre Educação Especial na Espanha, que teve por objetivo estabelecer diretrizes básicas para a formulação e reforma das políticas públicas e sistemas educacionais para atendimento das demandas de inclusão social.

De acordo com a Declaração de Salamanca (1994) toda criança possui características, interesses, habilidades e necessidades de aprendizagem que são únicas, e toda criança tem o direito à educação. Desta maneira ressalta:

Princípio fundamental da escola inclusiva é o de que todas as crianças devem aprender juntas, sempre que possível, independentemente de quaisquer dificuldades ou diferenças que elas possam ter. Escolas 
inclusivas devem reconhecer e responder às necessidades diversas de seus alunos, acomodando ambos os estilos e ritmos de aprendizagem e assegurando uma educação de qualidade à todos através de um currículo apropriado, arranjos organizacionais, estratégias de ensino, uso de recursos e parceria com as comunidades. Na verdade, deveria existir uma continuidade de serviços e apoio proporcional ao contínuo de necessidades especiais encontradas dentro da escola (BRASIL, 1994, p. 5).

A Declaração de Salamanca (1994) consiste em um documento de suma importância para elaboração de outras leis e conquistas no âmbito das políticas de inclusão e direitos humanos no Brasil; tanto foi e ainda é, que no ano de 2015, foi sancionada a Lei Brasileira de Inclusão n 13.146 que realça os direitos da pessoa com deficiência, especialmente os direitos educacionais. 0 artigo 27 , apregoa que:

[...] educação constitui direito da pessoa com deficiência, assegurado sistema educacional inclusivo em todos os níveis e aprendizado ao longo de toda a vida, de forma a alcançar o máximo desenvolvimento possível de seus talentos e habilidades físicas, sensoriais, intelectuais e sociais, segundo suas características, interesses e necessidades de aprendizagem (BRASIL, 2015).

Por conseguinte, o artigo $n^{\circ} 28$ anuncia que o poder público deve garantir as condições de acesso, permanência, participação e aprendizagem em todo sistema educacional brasileiro, contemplando todos os níveis, etapas e modalidades da Educação. Para que isso aconteça, deve-se ofertar serviços e recursos de acessibilidade que diminuam as barreiras e promovam a inclusão plena das pessoas com deficiências.

Nesse sentido, Mantoan (2003) afirma que a inclusão escolar tem o objetivo de atender todas as pessoas, principalmente as que possuem algum tipo de deficiência e pretende não deixar ninguém no exterior da escola comum e atendê-las desde o começo da vida escolar. Para isso, é necessário que haja mudanças na perspectiva educacional, pois a inclusão não atinge só as pessoas deficientes, mas todos da comunidade escolar. Desse modo:

A inclusão é uma provocação, cuja intenção é melhorar a qualidade do ensino, atingindo todos os alunos que fracassam em suas salas de aula. A distinção entre integração e inclusão é um bom começo para esclarecermos o processo de transformação das escolas, de modo que possam acolher, indistintamente, todos os alunos, nos diferentes níveis de ensino (MANTOAN, 2004, p. 40).

É importante saber que a inclusão não prevê a utilização de práticas escolares específicas para cada deficiência ou dificuldade de aprendizagem. Os professores terão que levar em conta suas limitações, explorando as suas possibilidades para que o ensino seja de qualidade e atenda a todos (MANTOAN, 2003). Santana (2009) afirma que educar os alunos com deficiência em sala de 
aula comum significa que todos devem receber educação de qualidade, independente de suas deficiências e diferenças, todos necessitam de oportunidades educacionais desafiadoras, que levem em conta suas próprias limitações.

Para Mantoan (2003) o professor é uma referência para o aluno e não apenas um instrutor, e por isso enfatiza a importância da formação para o desempenho do seu papel; tanto na construção do conhecimento, como na formação de atitudes e valores para exercer sua cidadania. Acerca da formação dos professores para atuação na Educação Especial, a LDBEN (BRASIL, 1996) em seu artigo 59, inciso III, aponta que para atuação nessa modalidade os professores precisam ser especializados com formação em nível médio ou superior, de modo que sejam capacitados para integração desses educandos nas classes comuns.

O artigo $9^{\circ}$ da nova Política Nacional de Educação Especial: Equitativa, Inclusiva e com Aprendizado ao Longo da Vida (BRASIL, 2020) estabelece onze ações a serem implementadas a formação dos profissionais da educação para o atendimento educacional e o atendimento educacional especializado, dentre as quais, vale destacar o incentivo na promoção de qualificação de professores para atuarem na Educação Especial em cursos como: licenciatura em Educação Especial; especialização em Educação Especial; Pós Graduação Stricto Sensu em Educação Especial ou áreas afins; cursos de formação continuada em Educação Especial; e outros que entram como prioridade desta política nacional (BRASIL, 2020). Dessa forma, Mantoan (2003) afirma que é preciso investir na formação e capacitação dos professores:

Não se pode descuidar da realização dessa formação e deve-se estar atento ao modo pelo qual os professores aprendem, para se profissionalizar e para aperfeiçoar seus conhecimentos pedagógicos, e também a como reagem às novidades, aos novos possíveis educacionais (MANTOAN, 2003, p. 43).

Assim, a formação dos professores é importante no processo de inclusão e na busca de novas posturas e habilidades que permitam problematizar, compreender e intervir nas diferentes situações que se deparam, além de auxiliarem na construção de uma proposta pedagógica e ações mais inclusivas (ROCHA, 2017).

A formação docente capaz de corresponder às demandas de uma educação inclusiva, requer um processo de formação e reflexão profunda da prática e do ambiente escolar. Sassaki (2005) propõem seis dimensões de saberes que envolvem a acessibilidade, sendo: acessibilidade metodológica, arquitetônica, comunicacional, atitudinal, instrumental e programática. A acessibilidade metodológica requer habilidades para utilização das tecnologias assistivas para potencializar a aprendizagem em todo processo de ensino. Para isso, o professor precisa se sentir competente, especialmente para propor intervenções que vem de encontro às necessidades da sua turma ou do seu aluno, usando da criatividade e diferentes estratégias. 
Para Sassaki (2005) as modificações metodológicas requerem repensar nos sistemas de avaliação, nos processos educativos e nas práticas pedagógicas. A acessibilidade arquitetônica, o professor precisa ser capacitado a pensar nas barreiras que precisam ser removidas para garantir não apenas o acesso, mas a permanência das pessoas com deficiência nas instituições escolares, de modo que o professor reconheça as reais necessidades de ampliação dos espaços de socialização para que ocorra a aprendizagem.

A acessibilidade comunicacional está relacionada em saber se comunicar de forma efetiva, superando as práticas de improviso e adivinhação, enquanto que para o saber atitudinal cabe ao professor valorizar as diferenças, de maneira que as igualdades de oportunidades sejam pensadas e colocadas em ação, reconhecendo as diferenças, valorizando-as de modo que as deficiências não sejam obstáculos (SASSAKI, 2005).

Nos aspectos relacionados ao saber instrumental é a capacidade que o docente tem de produzir seus próprios materiais, mesmo com baixa tecnologia, adequando de forma específica para necessidade de cada aluno, e que muitas vezes pode ser um recurso comum para toda turma. O saber pragmático envolve as diversas mudanças na formação de professores que implicam nas práticas educativas escolares, e para o autor, o desafio é que exista uma formação de professores que supere as orientações médico-psicológicas que se assentam basicamente nos aspectos biológicos e funcionais, fragmentando 0 conhecimento, de maneira que não responde às demandas pedagógicas do processo de ensino e de aprendizagem (SASSAKI, 2005).

Nesse sentido, o presente estudo propõe analisar a percepção de três professores que atuam no ensino de crianças com Síndrome de Down na Educação Infantil, bem como discutir a importância da formação destes professores no processo de inclusão escolar.

\section{Encaminhamentos metodológicos}

Esse estudo assume um caráter qualitativo, o qual buscou identificar aspectos a respeito da inclusão; embasamento teórico e/ou experiencial acerca da Síndrome de Down. Nesse viés, buscou-se discutir os desafios para inclusão de estudantes da Educação Especial na modalidade Educação Infantil.

Os dados analisados foram coletados por meio de uma entrevista semiestruturada realizada com três professoras atuantes na Educação Infantil, posterior sua autorização e assinatura do Termo de Consentimento Livre Esclarecido (TCLE), de modo que fossem preservadas suas identidades. $O$ movimento analítico está embasado na Análise Textual Discursiva (ATD) (MORAES; GALIAZZI, 2014), correspondente a um conjunto de métodos variados que analisam os dados qualitativamente, com finalidade de produzir novas compreensões sobre os fenômenos e discurso.

O processo de análise baseado na ATD ocorre mediante etapas sequenciais, a saber: desconstrução e unitarização, categorização, elaboração de metatexto e emergência do novo. Na etapa de unitarização, decorrente da 
transcrição das entrevistas, há a fragmentação dos textos. Esse movimento originou as unidades de análise e codificação das professoras participantes ( $P 1$, P2 e P3). O processo de categorização envolve o estabelecimento das relações entre as unidades; na qual as categorias podem ser definidas a priori ou emergir a partir da análise. Já a construção dos metatextos compreende a descrição e interpretação dos excertos, a partir da teorização e subsídio teórico de interesse, no qual são produzidos novos argumentos para a compreensão do fenômeno em questão de forma a estabelecer a emergência do "novo"(MORAES, 2003).

As categorias a priori correspondem às construções do pesquisador que são elaboradas a partir das teorias que fundamentam o trabalho; já as emergentes, ou posteriori, são construções a partir das informações do corpus, e estão associadas aos métodos indutivos e intuitivos. Para essa investigação, as categorias foram elaboradas de acordo com o material analisado, ou seja, categorias emergentes. Desta maneira, elaborou-se uma categoria denominada "Inclusão", que buscou identificar a compreensão das professoras acerca do conhecimento sobre a Educação Especial Inclusiva, considerando aspectos específicos, a saber: unidade 1 (U1) intitulada "Conhecimentos sobre a inclusão"; unidade 2 (U2) "Conhecimento sobre a Síndrome de Down" e unidade 3 (U3) "Desafios da Inclusão na Educação Infantil". O quadro 1 a seguir, apresenta esta categoria, bem como as unidades supracitadas.

Quadro 1 - Categoria, unidades e objetivos

\begin{tabular}{|c|c|c|}
\hline CATEGORIA & UNIDADES & OBJETIVO \\
\hline \multirow{4}{*}{ INCLUSÃo } & $\begin{array}{c}\text { Conhecimentos sobre a Inclusão } \\
\text { (U1) }\end{array}$ & $\begin{array}{l}\text { Identificar os conhecimentos das } \\
\text { professoras participantes sobre a } \\
\text { inclusão. }\end{array}$ \\
\cline { 2 - 3 } & $\begin{array}{c}\text { Conhecimentos sobre a } \\
\text { Síndrome de Down (U2) }\end{array}$ & $\begin{array}{c}\text { Analisar os conhecimentos das } \\
\text { professoras sobre a Síndrome de } \\
\text { Down. }\end{array}$ \\
\cline { 2 - 3 } & $\begin{array}{c}\text { Desafios da Inclusão na } \\
\text { Educação Infantil (U3) }\end{array}$ & $\begin{array}{c}\text { Destacar os desafios encontrados } \\
\text { pelas professoras durante o } \\
\text { processo de inclusão escolar na } \\
\text { Educação Infantil. }\end{array}$ \\
\hline
\end{tabular}

Fonte: Dados da Pesquisa (2021).

Na próxima seção iremos discorrer os resultados e discussões sobre os dados obtidos com base na entrevista de P1, P2 e P3.

\section{Resultados e discussões}

Os dados coletados correspondem à participação voluntária de três professoras na pesquisa que trabalham e já trabalharam com crianças com Síndrome de Down. As professoras possuem formação em Pedagogia, sendo que trabalham no mesmo Centro Municipal de Educação Infantil (CMEI) de uma cidade situada no norte do estado do Paraná. A P1 possui 36 anos de idade e (c) (1) (3)

Perspectivas em Diálogo, Naviraí, v. 09, n. 19, p. 105-121, jan./abr. 2022. 
atua na Educação Infantil há 7 anos e no momento está no cargo de coordenadora do CMEI. A P2 possui 36 anos de idade e seu tempo de atuação na Educação Infantil é de 10 anos, atualmente ela é supervisora do CMEI. A P3 tem 44 anos de idade e atua na Educação Infantil há 15 anos, atualmente exerce a função de professora regente e trabalha com uma criança com Síndrome de Down. P1 e P2 trabalharam com crianças com síndrome de Down em algum momento de suas atuações enquanto docentes. A seguir, o quadro 2 destaca os excertos representativos acerca dos conhecimentos que as professoras possuem sobre a inclusão na Educação Infantil.

\section{Quadro 2 - Conhecimento sobre a inclusão na Educação Infantil}

\begin{tabular}{|c|l|}
\hline \multicolumn{1}{|l|}{ U1 } \\
$\begin{array}{c}\text { CONHECIMENTOS DAS } \\
\text { PROFESSORAS SOBRE } \\
\text { A INCLUSÃO }\end{array}$ & $\begin{array}{l}\text { "Inclusão é o direito que a criança que possui alguma } \\
\text { deficiência têm de conviver com as demais crianças da sua } \\
\text { idade" (P1). } \\
\text { "É o direito que a criança tem de ser atendida na sua } \\
\text { totalidade" (P2). } \\
\text { "É receber, acolher da mesma forma na sala de aula todas } \\
\text { as crianças, independente de cor, classe social, condições } \\
\text { físicas ou psicológicas, pois todos têm direitos iguais" (P3). } \\
\text { "A criança com necessidades especiais tem o direito de ter } \\
\text { acesso ao convívio com outras crianças na rede regular, irá } \\
\text { ajudar no desenvolvimento da linguagem, habilidades } \\
\text { motoras, cognitivas e interação" (P3). }\end{array}$ \\
\hline
\end{tabular}

Fonte: Dados da Pesquisa (2021).

Ao observar as respostas das professoras da Educação Infantil, percebese que todas possuem um conhecimento incipiente sobre a inclusão escolar de alunos público alvo da Educação Especial, ou seja, não mencionam leis, documentos e público alvo. P3 afirma que a inclusão "É receber e acolher [...]", o que pode ser observado nas contribuições de Mantoan (2003) ao assegurar que a inclusão tem como objetivo atender todas as pessoas, principalmente as que possuem algum tipo de deficiência, não deixando nenhuma criança de fora da vida escolar, priorizando o atendimento desde os primeiros anos de vida.

A Constituição Federal de 1988 em seu artigo 205 determina que a educação é direito de todos e dever do Estado e da família, podemos observar que a P2 evidencia este conhecimento. Outro aspecto relevante no relato da professora P3 é a importância da inclusão escolar acontecer desde a Educação Infantil, sendo destacado pela professora a importância do desenvolvimento das habilidades cognitivas, motoras, de interações e linguagem.

A criança com necessidades especiais tem o direito de ter acesso ao convívio com outras crianças na rede regular, irá ajudar no desenvolvimento da linguagem, habilidades motoras, cognitivas e interação (P3). 
P1 concorda com a fala de P3, porém a P1 afirma que os alunos com necessidades especiais levam um tempo maior para obter o mesmo aprendizado que as outras crianças que não possuem deficiências. Nesse sentido, é necessário respeitar o tempo de aprendizado de cada indivíduo e de acordo com Dea e colaboradores (2009), as crianças com deficiências possuem várias limitações e dificuldades, por isso é necessário que haja a inclusão desde os primeiros anos de vida, e com paciência e persistência as crianças podem desenvolver sua aprendizagem em diversos campos do saber.

A Declaração de Salamanca (1994) realça que o bom desempenho das escolas inclusivas depende muito da identificação precoce, da avaliação e da estimulação das crianças com necessidades especiais. O documento incentiva a criação de uma assistência infantil e programas que precisam ser desenvolvidos para que as crianças de até 6 anos de idade possam ser avaliadas e estimuladas para promoção do seu desenvolvimento físico, intelectual e social, de modo que os prepare para as demandas escolares.

Além disso, os bons resultados na Educação inclusiva estão ligados à preparação, formação e capacitação dos professores, que precisam ser priorizados nesse processo. Mantoan (2011) afirma que há muitos meios para capacitação dos professores, tanto em cursos de Pedagogia, nas pós-graduação, na formação continuada oferecida pelos municípios, no acervo das clínicas e instituições que atendam indivíduos com deficiência.

A seguir, no quadro 3, são expostos os excertos representativos sobre os conhecimentos que as professoras possuem sobre a Síndrome de Down (U2).

\section{Quadro 3 - Conhecimento sobre a Síndrome de Down}

\begin{tabular}{|c|c|}
\hline $\begin{array}{c}\text { U2 } \\
\text { CONHECIMENTOS } \\
\text { SOBRE AS } \\
\text { PROFESSORAS } \\
\text { POSSUEM SOBRE A } \\
\text { SÍNDROME DE DOWN }\end{array}$ & $\begin{array}{l}\text { "É uma alteração na divisão celular comprometendo o } \\
\text { cromossomo } 21 \text { (onde ficam } 3 \text { cromossomos). Algumas } \\
\text { características como: rosto arredondado e levemente } \\
\text { achatado, mãos menores e dedinhos mais curtos, hipotonia } \\
\text { muscular e em alguns casos cardiopatia" (P1). } \\
\text { "É um distúrbio genético causado, quando uma divisão } \\
\text { celular anormal resulta em material genético extra do } \\
\text { cromossomo } 21 \text { " (P2). } \\
\text { "A criança com a Síndrome tem como singularidade a } \\
\text { hipotonia, essa fragilidade, faz cansar mais rapidamente as } \\
\text { atividades, têm períodos de concentração menor e } \\
\text { necessita de rotina para estruturar melhor seu } \\
\text { aprendizado" (P3). }\end{array}$ \\
\hline
\end{tabular}

Fonte: Dados da Pesquisa (2021).

A partir da análise dos excertos, verifica-se que todas as professoras possuem algum conhecimento sobre a SD, como por exemplo suas características fenotípicas e os comportamentos dos indivíduos que possuem Síndrome de Down. P2, ressalta informações sobre a causa: "É um distúrbio 
genético causado, quando uma divisão celular anormal resulta em material genético extra do cromossomo 21". Em concordância com essa resposta, destacamos que Schwartzman (2003) afirma, que na maioria dos casos a Síndrome de Down, é causada por um erro na divisão celular que causa modificações no desenvolvimento embrionário.

Segundo Dea; et al; (2009), a Síndrome de Down é uma anomalia genética causada pela divisão celular dos cromossomos, e pode estar presente em qualquer tipo de pessoa, ela não distingue raça, sexo, e outros, além disso a criança com Síndrome de Down carrega a genética de seus pais e podem até mesmo ter semelhança com sua família, no entanto, cada indivíduo possui suas particularidades, intensificando ou não a sua deficiência mental ou atraso motor. Assim, a SD é uma condição humana geneticamente determinada, sendo um modo de estar no mundo que representa a diversidade humana (BRASIL, 2013).

As características físicas da pessoa com Síndrome de Down, são destacadas pela P1: "[...] rosto arredondado e levemente achatado, mãos menores e dedinhos mais curtos, hipotonia muscular e em alguns casos cardiopatia". Silva e Dessen (2002), afirmam que o indivíduo pode apresentar diversas características, e que devido a elas pode ocorrer um atraso no desenvolvimento da criança, portanto necessitam de estímulos desde os primeiros meses de vida.

Segundo Schwartzman (2003) podemos observar algumas características físicas que estão presentes em quase todas as pessoas com a Síndrome de Down, que podem ser notadas logo ao nascimento do bebê, como os olhos puxados, nariz pequeno e achatado, bocas e dentes pequenos, cabelos lisos e geralmente finos, as orelhas normalmente são de tamanho menores, os pés, mãos e a altura também são menores. Essas características são bastante marcantes e evidentes em todas as pessoas com Síndrome de Down.

A hipotonia muscular é causada por uma diminuição no tônus muscular, que resulta em flacidez e perda de força nos músculos; este sintoma está presente na maioria dos casos de pessoas com Síndrome de Down, causando atraso no desenvolvimento motor, principalmente na fase quando os bebês começam a sentar, engatinhar e andar. Observa-se no excerto, que a P3 pontua sobre a hipotonia, ao afirmar que "A criança com a Síndrome tem como singularidade a hipotonia, essa fragilidade, faz cansar mais rapidamente as atividades".

A este respeito, Dea e colaboradores (2009) afirmam que a pessoa com Síndrome de Down terá menor tonicidade muscular, por isso é fundamental que aconteça o trabalho de fortalecimento muscular, realizado por meio de estímulos, fisioterapia e esportes. Este trabalho é essencial para o desenvolvimento do indivíduo e deve ser realizado de forma adequada, de maneira com que englobe todas as necessidades da criança.

A seguir, serão apresentados os excertos que formam a terceira unidade de análise "Desafios das professoras perante a inclusão do aluno com Síndrome de Down na Educação Infantil" (U3), que será descrita no Quadro 4 abaixo: 


\section{Quadro 04 - Desafios da Inclusão na Educação Infantil}

\begin{tabular}{|c|c|}
\hline $\begin{array}{c}\text { U3 } \\
\text { DESAFIOS DAS } \\
\text { PROFESSORAS } \\
\text { PERANTE A INCLUSÃO } \\
\text { DO ALUNO COM } \\
\text { SÍNDROME DE DOWN } \\
\text { NA EDUCAÇÃO } \\
\text { INFANTIL }\end{array}$ & $\begin{array}{l}\text { "Trabalhei com duas alunos com Síndrome de Down, } \\
\text { percebi que o rendimento pedagógico se dá de forma mais } \\
\text { lenta, a coordenação motora também necessita de mais } \\
\text { estímulos, mas a cada avanço ficamos imensamente felizes } \\
\text { e realizadas" (P1). } \\
\text { "A dificuldade se dá mais na questão cognitiva até que a } \\
\text { criança seja capaz de interagir socialmente e responder } \\
\text { apropriadamente ao contexto imediato"(P2). } \\
\text { "Muitas vezes a maior dificuldade foi o sono, pois ela } \\
\text { estudava de manhã na APAE e no período da tarde no CMEI, } \\
\text { por diversas vezes dormia, as distrações, a falta de } \\
\text { interesse em realizar as atividades" (P3). }\end{array}$ \\
\hline
\end{tabular}

Fonte: Dados da Pesquisa (2021).

Nos excertos, observa-se que as professoras participantes da pesquisa encontram dificuldades no desenvolvimento do trabalho com a criança com Síndrome de Down. A P1 relata que trabalhou com duas alunas com Síndrome de Down, e nos dois casos a maior dificuldade foi o rendimento pedagógico, com dificuldades motoras o que necessitava de mais estímulo. Casarin (2003) afirma que há estudos que comprovam que o indivíduo com Síndrome de Down, possui uma sequência cronológica no desenvolvimento motor e psicológico, e por isso a área cognitiva do indivíduo é bastante afetada, causando um desenvolvimento mais lento. Assim, o processo de desenvolvimento e a aprendizagem se dão diferentes de outra criança com desenvolvimento típico. A hipotonia muscular contribui para que o desenvolvimento motor atrase, afetando diversas áreas da aprendizagem e desenvolvimento do sujeito.

A Síndrome de Down afeta desde o desenvolvimento físico quanto ao desenvolvimento mental, por isso a P2 ao trabalhar com o aluno com Síndrome de Down, relata que "a dificuldade se dá mais na questão cognitiva até que a criança seja capaz de interagir socialmente e responder apropriadamente ao contexto imediato". De acordo com o excerto, podemos ressaltar que Voivodic (2008) aponta que desde os anos iniciais de vida as crianças com SD possuem dificuldades em manter a atenção aos estímulos ao seu redor, ocasionando dificuldade de interação social.

A P3 relatou que sua maior dificuldade com questões relacionadas ao sono, pois a criança estudava na Associação de Pais e Amigos dos Excepcionais (APAE) no período da manhã, e ao chegar na escola a criança demonstrava cansaço pela rotina e não conseguia acompanhar o ritmo da turma. Nesse sentido, Mantoan (2003) orienta que os professores devem considerar cada aluno e suas próprias limitações, e o professor deve ser sensível ao compreender as especificidades de cada um.

É importante saber que a inclusão não prevê a utilização de práticas escolares para cada deficiência, mas que se elaborem atividades que atendam 
todas as crianças, suprindo todas as dificuldades que elas possuem. Conforme a análise dos excertos, percebe-se que as professoras apresentam dificuldades na inclusão de alunos com Síndrome de Down, provavelmente essa dificuldade seja causada pela falta de formação e capacitação profissional aos professores, pois ao responderem uma questão sobre a formação continuada ou preparação para receber em sala um aluno com Síndrome de Down, a P2 relata que:

[...] já participei de formação continuada, mas não teve muito aprofundamento, porém a preparação para receber na sala de aula o aluno com Síndrome de Down se dá na prática, não há uma receita pronta onde você lê e escreve (P2).

Já a P3 diz que "Sim, nos cursos de HTPC ${ }^{1}$ do município". De acordo com Mantoan (2003), é necessário mais do que a graduação e a pós-graduação, para os profissionais que trabalham na Educação Básica. É necessária uma formação em Educação Inclusiva, que deveria perpassar por todas as disciplinas do currículo, além da formação do professor, a experiências vividas dentro da sala de aula podem contribuir para a escolha de um melhor método de ensino para trabalhar em sala de aula. A autora ainda afirma que formar grupos de estudo na escola para a discussão e a compreensão dos desafios da inclusão, pode auxiliar professores a resolverem situações que podem aparecer durante suas aulas.

A formação teórica em Educação Inclusiva possibilita aos professores a capacidade de refletir sobre suas práticas, pressupostos e saberes que engendram as ações pedagógicas no âmbito da educação de pessoas que são público alvo da inclusão, sobretudo para que não sejam práticas improvisadas e vazias de reflexão teórica.

Apesar de relatarem que já participaram de cursos de formação e capacitação sobre atuação na inclusão de estudantes público alvo da Educação Especial, evidencia-se uma carência teórica no relato das professoras, o que demonstra a necessidade de maiores investimentos em formação continuada e capacitação de professores em serviço.

\section{Considerações finais}

Muitos avanços ocorreram nos últimos anos no campo educacional em termos de políticas públicas, inclusive no atendimento de pessoas com necessidades educacionais especiais. Toda essa história também acompanhou as mudanças acerca da pessoa com Síndrome de Down, que passa a ser vista como um ser humano capaz de viver em sociedade, desenvolver habilidades e aprender muitas coisas.

O contexto dessa pesquisa se deu na Educação Infantil, sendo essa a primeira etapa da Educação Básica, e segundo o artigo 29 da Lei de Diretrizes e Bases da Educação Básica, "tem como finalidade o desenvolvimento integral da criança até cinco anos" (BRASIL, 1996, art. 29). Portanto, os alunos com

${ }^{1}$ HTPC: Hora atividade para capacitação.

Perspectivas em Diálogo, Naviraí, v. 09, n. 19, p. 105-121, jan./abr. 2022. 
deficiência também possuem o direito à educação, uma vez que a inclusão escolar tem ganhado cada vez mais espaços nas instituições escolares e na sociedade.

Segundo Déa et al; (2009), as crianças com Síndrome de Down são capazes de aprender muitas coisas, como ler, escrever, dançar, e por isso devem receber estímulos desde os primeiros anos de vida para que haja um melhor desenvolvimento físico, cognitivo, emocional e social. A partir desta perspectiva, este trabalho buscou analisar a percepção de professoras perante a inclusão escolar do aluno com Síndrome de Down na Educação Infantil. As análises dos resultados identificaram que as participantes destacam a importância da inclusão escolar, bem como conhecem algumas características da Síndrome de Down, mas possuem dificuldades em exercer seu trabalho com a criança com essa síndrome.

Assim, evidencia-se a partir das três entrevistadas que os profissionais que atuam na educação escolar precisam de formação e capacitação para receber alunos com necessidades educacionais especiais, pois podem apresentar limitações causadas pela deficiência que exigirão um trabalho mais específico. No caso do aluno com Síndrome de Down, seu desenvolvimento físico e mental é afetado, causando um atraso em todos os aspectos, portanto os professores devem receber formação para o trabalho com esse sujeito que lhe dê condições de melhorias nos métodos de ensino e nos processos de aprendizagem. Para Mantoan (2011) existem diversas maneiras de capacitar os profissionais, como inúmeras especializações, porém o maior aprendizado acontece na vivência e na troca de experiências com outros professores, para que a inclusão tenha sucesso precisa de um bom profissional, do apoio da equipe pedagógica e de uma boa relação com família.

Esse estudo vem de encontro às necessidades de compreender o fenômeno da inclusão escolar, especialmente na Educação Infantil, no que tange aos desafios para que essa inclusão seja efetivamente de qualidade a partir da análise da percepção de professoras que atuam diretamente com os desafios da prática. Contudo, destaca-se a carência de mais estudos e pesquisas serem desenvolvidas abordando essa temática, sendo este um campo fértil para novas aprendizagens.

Esta pesquisa contribuiu para adquirir novos aprendizados e enriquecimento dos conhecimentos, demonstrando que inclusão escolar do aluno com Síndrome de Down é possível, mas necessita que os professores recebam orientações e preparações para poder lidar de maneira correta com a inclusão, que é um processo que envolve aluno, família, professor, equipe pedagógica e sociedade.

\section{REFERÊNCIAS}

BISSOTO, Maria Luísa. O desenvolvimento cognitivo e o processo de aprendizagem do portador de Síndrome de Down: revendo concepções e 
perspectivas educacionais. Ciência e Cognição, n.2, v.4, 2005. Disponível em www.cienciasecognicao.org.br. Acesso em 01 jun. 2020.

BRASIL. Constituição [da] República Federativa do Brasil. Brasília: Senado Federal, 1988.

BRASIL. Declaração de Salamanca: Sobre Princípios, Políticas e Práticas na Área das Necessidades Educativas Especiais. Brasília: Corde, 1994. Disponível em: http://portal.mec.gov.br/seesp/arquivos/pdf/salamanca.pdf. Acesso em: 26 set. 2019.

BRASIL. Lei de Diretrizes e Bases da Educacional. Lei 9394/96. Brasília, 1996.

BRASIL. Ministério da Saúde. Secretaria de Atenção à Saúde. Departamento de Ações Programáticas Estratégicas. Diretrizes de atenção à pessoa com Síndrome de Down. Brasília, 2013. Disponível em:http://bvsms.saude.gov.br/bvs/publicacoes/diretrizes_atencao_pessoa_sin drome_down.pdf. Acesso em: 26 set. 2020.

BRASIL. Ministério da Educação. Secretaria de Modalidades Especializadas de Educação. PNEE: Política Nacional de Educação Especial: Equitativa, Inclusiva e com Aprendizado ao Longo da Vida/ Secretaria de Modalidades Especializadas de Educação - Brasília; MEC. SEMESP. 2020.

CASARIN, Sonia. Aspectos psicológicos na Síndrome de Down. In: SCHWARTZMAN, José Salomão (Org). Síndrome de Down. 2ed. São Paulo: Memnom: Mackenzie, 2003. p. 263 - 280.

DÉA, Vanessa; BALDIN, Alexandre; DÉA, Vicente. Pressupostos básicos sobre síndrome de Down: Informações gerais sobre a síndrome de Down. In: DÉA, Vanessa; DUARTE, Edison (Org.). Síndrome de Down: informações, caminho e história de amor. São Paulo: Phorte, 2009. p.23-43.

GIONGO, Renata; BALDIN, Alexandre; CANEDO, Patricia. Possíveis patologias da criança com Síndrome de Down. In: DÉA, Vanessa; DUARTE, Edison (Org.). Síndrome de Down: informações, caminho e história de amor. São Paulo: Phorte, 2009. p. 43-55.

MANTOAN, Maria Teresa Eglér. Inclusão escolar: O que é? Por quê? Como fazer? São Paulo: Moderna, 2003.

MANTOAN, Maria Teresa Eglér. O Direito De Ser, Sendo Diferente, Na Escola. Brasília, 2004.

MANTOAN, Maria Teresa Eglér. A educação especial no Brasil: da exclusão à inclusão escolar. UNICAMP: São Paulo, 2011. 
MORAES, Roque. Uma tempestade de luz: A compreensão possibilitada pela análise textual discursiva. Ciência e Educação, v. 9, n. 2, p. $191-211$, 2003.

MORAES, Roque; GALIAZZI. Maria do Carmo. Análise Textual Discursiva. Ijuí: Editora: Unijuí, 2014.

ROCHA, Artur Batista de Oliveira. O papel do professor na Educação e Inclusiva. Ensaios Pedagógicos, v.7, n.2, 2017.

SASSAKI, Romeu Kazumi. Inclusão: o paradigma do século 21. Revista Inclusão, v. 1 , n. 1, p. 19-23, out. 2005.

SANTANA, Vanielen Erica. Inclusão da pessoa com síndrome de Down no ensino regular.Síndrome de Down: informações, caminho e história de amor. In: DÉA, Vanessa; DUARTE, Edison (Org.). Síndrome de Down: informações, caminho e história de amor. São Paulo: Phorte, 2009. p. 83-91.

SENO, Marília Piazzi; GIACHETI, Célia Maria; MORETTI-FERREIRA, Danilo. Linguagem narrativa e fluência na síndrome de down: uma revisão. Rev. CEFAC, São Paulo, v. 16, n. 4, p. 1311-1317, 2014.

SCHWARTZMAN, José Salomão. Síndrome de Down. 2 ed. São Paulo: Memnon: Mackenzie, 2003.

SERÉS, August; QUIÑONES, Ernesto; CASALDÁLIGA, Jaume; CORRETGER, Josep; TRIAS, Katy. Síndrome de Down, de A a Z. Ed. Saberes, 2011.

SILVA, Nara Liana Pereira; DESSEN, Maria Auxiliadora. Síndrome de Down: etiologia, caracterização e impacto na família. Interação em Psicologia, n.2, v. 6, jul./dez. 2002, p. 167-176. Disponível em http://bases.bireme.br. Acesso em 10 jun. 2020.

TELES, Elisa Rocha. Trissomia 21. Escola Secundária Sá da Bandeira Curso Tecnológico de Desporto, Lisboa, v. 12, n. 8, 2012.

VOIVODIC, Maria Antonieta.Inclusão escolar de crianças com Síndrome de Down. 5ed. Petrópolis, RJ: Vozes, 2008.

WERNECK, Claudia. Muito prazer, eu existo: um livro sobre as pessoas com Síndrome de Down. Rio de Janeiro: WVA, 1995. 